\title{
Q fever in cattle in some Egyptian Governorates: a preliminary study
}

\author{
Mayada Gwida ${ }^{1}$, Maged El-Ashker ${ }^{2 *}$, Mohamed El-Diasty ${ }^{3}$, Christina Engelhardt ${ }^{4}$, lahtasham Khan ${ }^{5}$ \\ and Heinrich Neubauer ${ }^{4}$
}

\begin{abstract}
Background: $\mathrm{Q}$ fever, caused by Coxiella burnetii, is a zoonosis with great public health significance and can cause financial losses to animal owners. The knowledge of the epidemiology of Q fever in Egypt is limited. Reports on this disease are scarce. In 2012 and 2013, we carried out this investigation to estimate the seroprevalence of antibodies to Coxiella burnetii in dairy cows of nine farms located in the lower Egyptian Governorates of Dakahlia, Damietta and Port Said. 1,194 blood sera were randomly collected from apparently healthy Holstein Friesian dairy cows. The collected sera were tested by ELISA for Coxiella burnetii antibodies.

Results: All farms tested positive with seroprevalences ranging from 2.9 to $26.7 \%$ on farms with less than 200 animals and 9.8 to 20.0\% in farms with more than 500 animals. 158 cows (13.2\%) had anti-Coxiella antibodies.

Conclusion: Q fever may be enzootic in the cattle herds investigated in Damietta, Port Said, and Dakahlia Governorates of the Nile delta in both smaller and larger herds. There is a need for further research on the impact of $\mathrm{Q}$ fever on both veterinary and public health. The results of this study should trigger more detailed epidemiological studies in ruminants as well as investigations into the etiology of atypical pneumonia and fever of unknown origin in humans.
\end{abstract}

Keywords: Coxiella burnetii, Cattle, Egypt, ELISA

\section{Background}

Q fever, a zoonotic disease caused by Coxiella burnetii, was first described in Queensland, Australia in 1935, after an outbreak of "flu-like illness" among slaughter house workers [1]. Since that time, it has been reported in most countries throughout the world [2,3]. Although Coxiella burnetii has been shown to infect a number of mammals, domestic ruminants especially sheep and goats are considered the main reservoir and source of human infection [4]. However, dairy cows may also be a source of human infection [2]. The main route of human infection is inhalation of contaminated aerosols, or dust containing bacteria shed by infected animals while milk may also play a role $[5,6]$. The clinical manifestations of $\mathrm{Q}$ fever in humans are highly variable and range from asymptomatic or mild disease with complete recovery

\footnotetext{
* Correspondence: maged_elashker@yahoo.com

${ }^{2}$ Department of Internal Medicine and Infectious Diseases, Faculty of Veterinary Medicine, Mansoura University, Mansoura 35516, Egypt

Full list of author information is available at the end of the article
}

(which probably occurs in most cases) to a variety of clinical signs such as acute flu-like illness, pneumonia, hepatitis and chronic endocarditis leading to inaccurate and delayed diagnosis [2]. In animals, reproductive problems can occur including abortion, stillbirth, retained placenta, infertility, and weak newborns causing severe financial loss to the owner [7]. Asymptomatic and symptomatic animals may release Coxiella burnetii in large quantities at parturition. Shedding can also occur into feces and urine of domestic ruminants which may play role in maintaining and disseminating the agent to the environment. Coxiellae can persist in the environment for long periods and may spread for long distances via the wind [8]. Coxiella burnetii can also be excreted into the milk of infected animals for many months and even years due to local infection of the mammary gland [9].

The isolation of the pathogen is a reliable diagnostic method, but it remains time-consuming and hazardous $[10,11]$. Since there is no characteristic clinical presentation for Q fever, epidemiological investigations mainly rely on serological tools. Hence, ELISA was found to be 
the method of choice for Q fever seroprevalence studies in man and animals [12]. Although $Q$ fever in man and animals is a notifiable disease in many countries, it remains poorly reported and its surveillance is severely neglected. In Egypt, little information is available regarding $Q$ fever and epidemiological studies are still scarce. Till now, no studies are available regarding the seroprevelance of Coxiella burnetii in dairy cattle in Dakahlia, Damietta, and Port Said Governorates, Egypt. We carried out this investigation to estimate the seroprevalence of Coxiella burnetii in the cattle populations in the respective regions.

\section{Methods}

\section{The selection criteria and sampling protocol}

The present study was conducted according to the principles of good clinical practice, and was approved by the Ethical Committee for Animal Experiments of Mansoura University. The present preliminary serological study included 1,194 apparently healthy Holstein Friesian dairy cows aged between 2 to 5 years on nine farms located in Dakahlia, Damietta and Port Said Governorates, Egypt (Table 1). These Governorates were chosen because convenient farms are located within a radius of 50, 85 and $135 \mathrm{~km}$ of Mansoura University (Figure 1). Five smaller holdings (less than 200 animals) and four holdings with more than 500 animals were included in the study. Ten $\mathrm{ml}$ of blood was collected from each animal through jugular venepuncture using plain tubes and needles. Each blood sample was labeled with the number of the respective animal. The collected blood samples were kept overnight at room temperature to allow blood clotting. On the next day, clear sera were collected and stored in cryotubes at $-20^{\circ} \mathrm{C}$ until further examination. The samples were collected during routine brucellosis investigation within the context of the current brucellosis control program in the region and informed consent for the $\mathrm{Q}$ fever investigation was given by the owners.

\section{Serological assay}

Serum samples were tested for Q fever antibodies (IgG) using ELISA (CHEKIT R; Idexx, Switzerland) according to the protocol of the manufacturer at a serum dilution of 1:400. The color development was measured as optical density (OD) with a spectrophotometer at $540 \mathrm{~nm}$. The cutoff for positivity was determined by the \%OD of the sample calculated as $\% \mathrm{OD}=100 \times(\mathrm{OD}$ value of test sample - OD value of negative control)/(OD value of positive control - OD value of the negative control). Samples with a \%OD value less than $30 \%$ were considered negative for Q fever antibodies, those between 30\% and $40 \%$ were considered suspect for $\mathrm{Q}$ fever antibodies, while those greater than $40 \%$ were considered positive.

\section{Results}

All herds included in this preliminary serological study had animals with anti-Coxiella antibodies ( $\mathrm{n}=158$; 13.2\%). In small herds with less than 200 dairy cows, the prevalence ranged from 2.9 to $26.7 \%$ while in herds with more than 500 animals the prevalence was between 9.8-20.0\% (Table 1). Seropositive herds were found in Damietta, Port Said and Dakahlia Governorates independent of the herd size (Table 1).

\section{Discussion}

Q fever is a common zoonotic disease in most parts of the world with epidemiological data varying from country to another. In humans as well as in animals, the prevalence of $\mathrm{Q}$ fever is often unknown, and is usually underestimated since the presentation of the disease impedes its clinical diagnosis. In Egypt, few studies have been carried out in relation to this infection and still little is known about the epidemiology of Coxiella burnetii and its public health significance $[13,14]$. Therefore, the need for a preliminary study to clarify the presence of Q fever in Lower Egypt in dairy cattle was evident.

Table 1 Summary of cattle farms and ELISA positive samples from three lower Egyptian Governorates in the Nile Delta

\begin{tabular}{|c|c|c|c|c|c|c|c|}
\hline Number of farm & Location & $\begin{array}{l}\text { Number of animals } \\
\text { in the farm }\end{array}$ & $\begin{array}{l}\text { Number of } \\
\text { collected samples }\end{array}$ & $\begin{array}{l}\text { Number of } \\
\text { positives }\end{array}$ & $\%$ & $\begin{array}{l}\text { Number of } \\
\text { suspects }\end{array}$ & $\%$ \\
\hline Farm 1 & Damietta & 1.200 & 50 & 10 & 20 & 1 & 2 \\
\hline Farm 2 & Damietta & 150 & 15 & 4 & 26.7 & 0 & 0 \\
\hline Farm 3 & Dameitta & 50 & 38 & 10 & 26.3 & 5 & 13.2 \\
\hline Farm 4 & Damietta & 600 & 336 & 50 & 14.9 & 16 & 4.8 \\
\hline Farm 5 & Port Said & 520 & 100 & 18 & 18 & 1 & 1 \\
\hline Farm 6 & Dakahlia & 170 & 167 & 26 & 15.6 & 7 & 4.2 \\
\hline Farm 7 & Dakahlia & 70 & 63 & 3 & 4.8 & 1 & 1.6 \\
\hline Farm 8 & Dakahlia & 70 & 69 & 2 & 2.9 & 1 & 1.5 \\
\hline Farm 9 & Dakahlia & 600 & 356 & 35 & 9.8 & 9 & 2.5 \\
\hline Total & & 3430 & 1194 & 158 & 13.2 & 41 & 3.75 \\
\hline
\end{tabular}




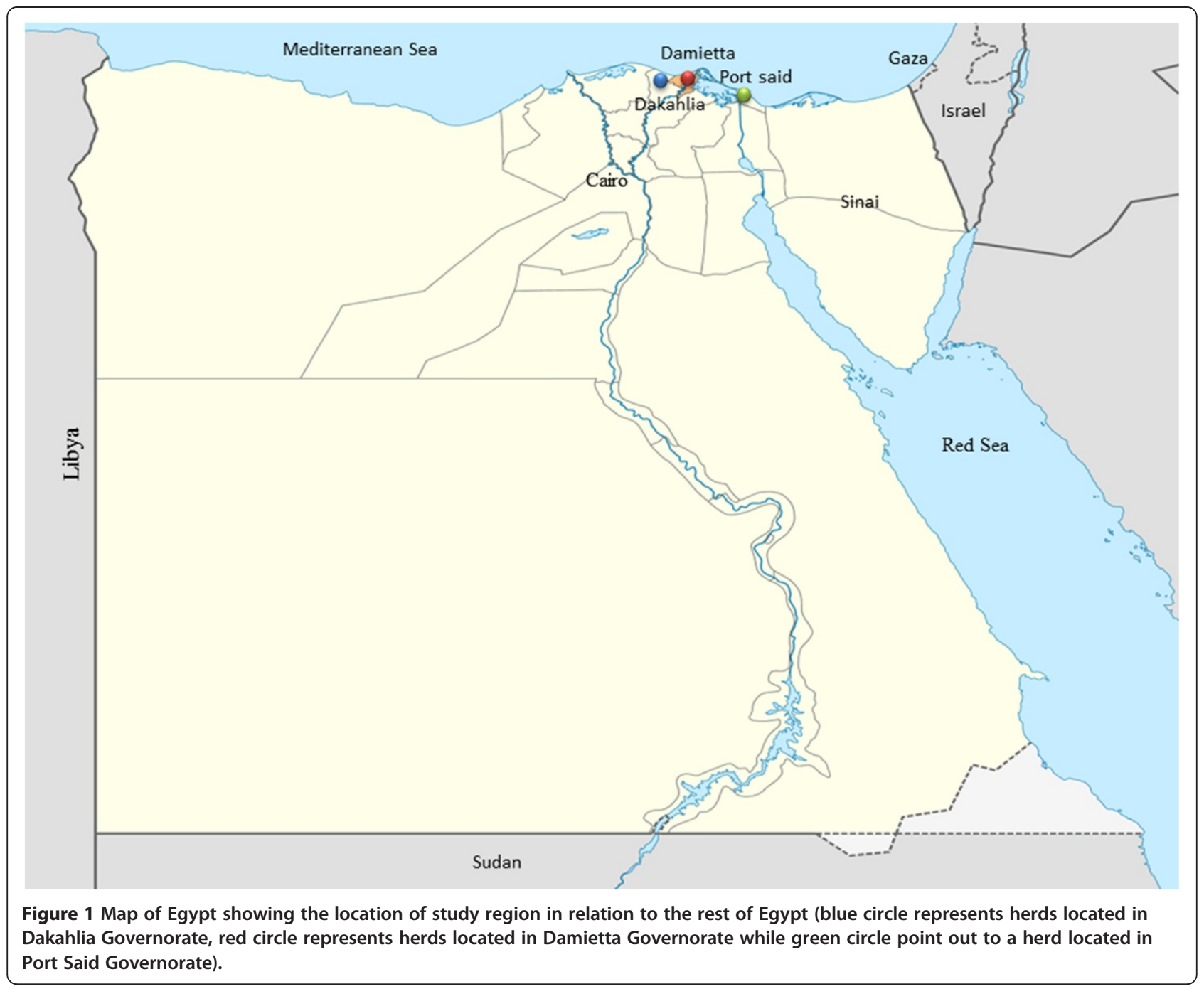

In general, $\mathrm{Q}$ fever was not considered a potential problem in Egypt before 1995 as demonstrated by the virtual absence of reports on this disease before that time [15]. In 1995, Botros et al. described a seroprevalence of $25 \%$ in the risk group of cattle keepers. However, in the same study variable seroprevalence rates were reported; $20 \%$ among adult Egyptian blood donors in the Suez Canal area $(\mathrm{n}=358) ; 16 \%$ in the Nile Valley $(\mathrm{n}=501)$ and $10 \%$ in the Nile Delta $(n=427)$. On the other hand, in sheep and goats the seroprevalence rates were reported to be $22.5 \%$ and $16.5 \%$ in the North Sinai, respectively [13]. The recent finding of seropositive animals in Giza, Cairo and El-Fayum districts (7 of 54 animals examined) suggested that Q Fever may indeed be circulating in cattle herds in Egypt. In the present investigation, the seropositivity of Coxiella burnetii was lower than that reported from Nigeria, Sudan, Zimbabwe, Cameroon and Togo [16-20], but higher than those reported from Trinidad, Chad or Iran $[3,21,22]$. However, it should be noted that these studies differ in their design and laboratory and statistical analyses, thereby limiting their comparability with our results [21]. To better understand the epidemiology of Coxiella burnetii in the study area, further research will include the investigation of milk samples, uterine discharges and abortion material for the presence of the organism. These materials were not available in our study, although one of the ELISA positive serum samples from herd 1 was positive for Coxiella burnetii DNA corresponding to 9.5 genome equivalents by real time PCR. Our dairy cows were clinically healthy and no ticks, as potential reservoirs, were observed on the animals or in the housing areas upon examination. Generally, early acute Q fever infection is characterized by the presence of circulating Coxiella burnetii DNA in the absence of circulating antibodies (seronegative stage). Subsequently, IgM antibodies to phase II antigens (IgM-II) appear (seropositive stage) with circulating Coxiella burnetii DNA still present in most cases. Thereafter, phase II IgG (IgG-II), phase I 
IgM (IgM-I) and phase I IgG (IgG-I) antibodies appear with coinciding disappearance of circulating Coxiella burnetii DNA allowing for distinguishing time dependent serologic profiles [23]. Thus, it seems likely that the ELISA positive cattle were exposed to Coxiella burnetii in the past and some of these animals may have been chronically infected. These animals may be responsible for maintenance of the chain of infection. However, the ways of transmission still require further investigation.

A limitation of this study is that farms were selected by convenience sampling and are therefore not representative of the entire cattle population. However, this study is valuable in that it provides evidence for the circulation of Coxiella burnetii in the study area and people who deal with cattle may therefore be at risk to contract $\mathrm{Q}$ fever. Further epidemiological investigations are warranted. Given the lack of recent published data on Q fever in Egypt, the finding that all investigated herds included at least one seropositive animal is concerning. This conclusion is in line with a study in animal keepers which demonstrated that exposure was not uncommon [15]. In this regard, a recent interesting study dealing with the clinical spectrum of fever of unknown origin (FUO) among adult Egyptian patients admitted to Ain Shams University Hospitals has found that brucellosis and infective endocarditis were the most common causes of FUO (41.94\%) followed by malignancies (30.11\%) and autoimmune diseases (15.05\%) while diagnosis was not reached in (12.9\%) of patients [24]. Therefore, there is an urgent need for future studies on the impact of $\mathrm{Q}$ fever on both veterinary and public health.

\section{Conclusion}

The results presented herein offer evidence that Q fever may be enzootic in cattle herds in Damietta, Port Said, and Dakahlia Governorates of the Nile delta region. In addition, the dimension of economic losses caused by abortion and mastitis has to be quantified. There is also an urgent need for future studies on the impact of $Q$ fever on both veterinary and public health. The results of this study should trigger more detailed epidemiological studies in ruminants as well as investigation into the etiology of atypical pneumonia and fever of unknown origin in humans.

\section{Competing interests}

The authors declare that they have no competing interests.

\section{Authors' contributions}

MG designed and coordinated the study, carried out the experimental work, data analysis, writing of the manuscript and helped to draft and review the manuscript. MEA responsible for clinical examinations and participated in samples collection, take part in writing of the manuscript, helped to draft the manuscript, review of the final manuscript, approval for publication and responsible for all correspondence to the journal. MED participated in samples collection. CE participated in PCR assays. IK helped to draft the manuscript. HN participated in the design and coordination of the study, evaluation of the PCR assays and helped to draft and reviews the manuscript. All authors approved the final version of the manuscript for publication.

\section{Acknowledgement}

This work was in parts funded by the German Federal Foreign Office program: Deutsches Partnerschaftsprogramm für biologische Sicherheit und Gesundheitssicherstellung. The authors would like to thank the Egyptian Ministry of High Education and cultural affairs and Missions sector for their encouragement and appreciated their cooperation regarding the post-Doctor scholarship given to the first author to FLI, Jena, Germany.

\section{Author details}

${ }^{1}$ Department of Hygiene and Zoonoses, Faculty of Veterinary Medicine, Mansoura University, Mansoura 35516, Egypt. ' Department of Internal Medicine and Infectious Diseases, Faculty of Veterinary Medicine, Mansoura University, Mansoura 35516, Egypt. ${ }^{3}$ Animal Health Research Institute-Mansoura Provincial Laboratory, Mansoura, Egypt. ${ }^{4}$ Friedrich-Loeffler-Institut (FLI), Institute of Bacterial Infections and Zoonoses, 07743 Jena, Germany. ${ }^{5}$ University of Veterinary and Animal Sciences, Lahore, Pakistan.

Received: 28 August 2014 Accepted: 25 November 2014 Published: 7 December 2014

\section{References}

1. Derrick EH: Q fever, a new fever entity clinical features, diagnosis and laboratory investigation. Rev Infect Dis 1983, 5:790-800.

2. Maurin M, Raoult D: Q fever. Clin Microbiol Rev 1999, 12:518-553.

3. Khalili M, Sakhaee E: An update on a serologic survey of $Q$ fever in domestic animals in Iran. Am J Trop Med Hyg 2009, 80:1031-1032.

4. Berri M, Souriau A, Crosby M, Crochet D, Lechopier P, Rodolakis A: Relationship between the shedding of Coxiella burnetii, clinical signs and serological responses of 34 sheep. Vet Rec 2001, 148:502-505.

5. Arricau-Bouvery N, Souriau A, Lechopier P, Rodolakis A: Experimental Coxiella burnetii infection in pregnant goats: excretion routes. Vet Res 2003, 34:423-433.

6. Gwida M, El-Ashker M, Khan I: Q fever: a re-emerging disease? J Vet Sci Technol 2012, doi:10.4172/2157-7579.1000120.

7. Woldehiwet Z: Q fever (coxiellosis): epidemiology and pathogenesis. Res Vet Sci 2004, 77:93-10.

8. Kirkan S, Kaya O, Tekbiyik S, Parin U: Detection of Coxiella burnetii in cattle by PCR. Tur J Vet Anim Sci 2008, 32:215-220.

9. Muskens J, Van Engelen E, Van Maanen C, Bartels C, Lam TJ: Prevalence of Coxiella burnetii infection in Dutch dairy herds based on testing bulk tank milk and individual samples by PCR and ELISA. Vet Rec 2011, 68:79.

10. Fournier PE, Marrie TJ, Raoult D: Diagnosis of Q fever. J Clin Microbiol 1998, 36:1823-1834.

11. Arricau-Bouvery $N$, Rodolakis $A$ : Is $Q$ fever an emerging or re-emerging zoonosis? Vet Res 2005, 36:327-349.

12. Rousset E, Duquesne V, Russo P, Aubert M: Q Fever. In Manual of Diagnostic Tests and Vaccines for Terrestrial Animals. 6th edition. Paris, France: OIE; 2010.

13. Mazyad SA, Hafez AO: Q fever (Coxiella burnetii) among man and farm animals in North Sina. J Egypt Soc Parasitol 2007, 37:135-142.

14. Nahed GH, Abdel-moein AK: Seroprevalence of Coxiella burnetii antibodies among farm animals and human contacts in Egypt. J Am Sci 2012, 8:619-621.

15. Botros BA, Soliman AK, Salib AW, Olsen J, Hibbs RG, Williams JC, Darwish M, EL-Tegani A, Watts D: Coxiellla burnetii antibody prevalence in North-East Africa determined by enzyme immunoassay. J Trop Med Hyg 1995, 98:173-178.

16. Adesiyun AA, Jagun AG, Tekdek LB: Coxiella burnetii antibodies in some Nigerian dairy cows and their suckling calves. Int J Zoonoses 1984, 11:155-160.

17. Hussien MO, ElFahal AM, Enan KA, Taha KM, Mohammed MS, Salih DA, Mohammadain SI, Saeed AA, El-Hussein AM: Seroprevalence of Q fever in Goats of the Sudan. Vet World 2012, 5:394-397. doi:10.5455/ vetworld.2012.394-397.

18. Kelly PJ, Matthewman LA, Mason PR, Raoult D: Q fever in Zimbabwe. A review of the disease and the results of a serosurvey of humans, cattle, goats and dogs. S Afr Med J 1993, 83:21-25. 
19. Scolamacchia F, Handel IG, Fe'vre EM, Morgan KL, Tanya VN, Bronsvoort BM: Serological patterns of brucellosis, leptospirosis and Q fever in Bos indicus cattle in Cameroon. PLoS One 2010, 5:e8623. doi:10.1371/journal. pone.0008623.

20. Dean AS, Bonfoh B, Kulo AE, Boukaya GA, Amidou M: Epidemiology of brucellosis and $\mathrm{Q}$ fever in linked human and animal populations in northern togo. PLoS One 2013, 8:e71501. doi:10.1371/journal.pone.0071501.

21. Adesiyun AA, Cazabon EP: Seroprevalences of brucellosis. Q fever and toxoplasmosis in slaughter livestock in Trinidad. Rev Elev Med Vet Pays Trop 1996, 49:28-30.

22. Schelling E, Diguimbaye C, Daoud S, Nicolet J, Boerlin P, Tanner M, Zinsstag J: Brucellosis and Q-fever seroprevalences of nomadic pastoralists and their livestock in Chad. Prev Vet Med 2003, 61:279-293.

23. Guatteo R, Seegers H, Taurel AF, Joly A, Beaudeau F: Prevalence of Coxiella burnetii infection in domestic ruminants: a critical review. Vet Microbiol 2011, 149:1-16.

24. Ali-eldin FA, Abdelhakam SM, Ali-eldin ZA: Clinical spectrum of fever of unknown origin among adult Egyptian patients admitted to Ain Shams University Hospitals: a hospital based study. J Egypt Soc Parasitol 2011, 41:379-386.

doi:10.1186/1756-0500-7-881

Cite this article as: Gwida et al:: $Q$ fever in cattle in some Egyptian

Governorates: a preliminary study. BMC Research Notes 2014 7:881.

\section{Submit your next manuscript to BioMed Central and take full advantage of:}

- Convenient online submission

- Thorough peer review

- No space constraints or color figure charges

- Immediate publication on acceptance

- Inclusion in PubMed, CAS, Scopus and Google Scholar

- Research which is freely available for redistribution 